DNA là $8,7 \times 10^{6} \pm 1,3 \times 10^{7}$ copies $/ \mathrm{mL}$. Có $3 / 32$ bệnh nhân tải lượng HBV dưới ngưỡng, cụ thể: 1 bệnh nhân <58,2 copies/mL, 1 bệnh nhân <116 copies $/ \mathrm{mL}$ và 1 bệnh nhân $<100$ copies $/ \mathrm{mL}$.

- 63,7\% bệnh nhân xơ gan Chid-pugh $A$, Child-pugh (4,9\%).

- Nồng đô trung bình của AFP, AFP-L3, PIVKA

II ở nhóm bệnh nhân xơ gan là $86,8 \mathrm{ng} / \mathrm{mL}$; 6,2\%; 246,98 mAU/mL

\section{TÀl LIỆU THAM KHẢO}

1. Hyuna Sung, Jacques Ferlay, et al (2021) Global cancer statistics 2020: GLOBOCAN estimates of incidence and mortality worldwide for 36 cancers in 185 countries. CA: a cancer journal for clinicians.

2. Lương Ngoc Khuê, Mai Trong Khoa và CS (2020) Hưởng dẩn chẩn đoán và điều trị một số bênh ung bướu. Bô Y tế, tr. 900-935.

3. Rícco G et al. (2018). Impact of etiology of chronic liver disease on hepatocellular carcinoma biomarkers. Cancer Biomark; 21(3):603-612

4. Lim T.S., D.Y. Kim, K.-H. Han, et al (2016).
Combined use of AFP, PIVKA-II, and AFP-L3 as tumor markers enhances diagnostic accuracy for hepatocellular carcinoma in cirrhotic patients. Scandinavian journal of gastroenterology, 51(3), 344-353.

5. Hann H.-W., D. Li, H. Yamada, et al (2014). Usefulness of highly sensitive AFP-L3 and DCP in surveillance for hepatocellular carcinoma in patients with a normal Alpha-Fetoprotein. J Med Microb Diagn, 3(1), 1-6.

6. Ngô Qúy Châu (2020), Bệnh học nội khoa, 4, ed, Vol. 2, Nhà xuất bản Y học, Hà Nội.

7. Ngô Thị Thanh Quýt, Nguyển Phương, Lê Thành Lý, Bùi Hữu Hoàng (2010), "Chẩn đoán mức độ xơ hóa gan bằng phương pháp đo độ đàn hồi gan trên bệnh nhân bệnh gan mạn", Tap chí Y Hoc Thành phổ Hồ Chí Minh, 14(1), tr.161-166.

8. Trân Ânh Tuyết (2006), Khảo sát mối tương quan giữa các yếu tố nguy cơ và giãn tĩnh mạch thực quản trên bệnh nhân xơ gan, Luân văn chuyên khoa cấp II, Đaai học Y-Dược TP.Hố Chí Minh.

9. Lâm Hoàng Cát Tiên (2005), Khảo sát giá trì của phương pháp chẩn đoán không xâm lấn trong xơ gan còn bù, Luận văn bác sĩ nội trú, Đại họ Y Dược TP.Hồ Chí Minh.

\title{
MộT SỐ YẾU TỐ LIÊN QUAN ĐẾN MỨC Độ TỰ TIN TRONG GIAO TIẾP CỦA ĐIỀU DƯỠNG VIÊN TAI MộT Số BÊ̂NH VIỆN TỈNH THÁI NGUYÊN VÀ CAO BẰNG NĂM 2021
}

\section{Nguyễn Hoàng Long ${ }^{1}$}

\section{TÓM TẮT}

Đăt vấn đề: Mức độ tự tin quyết định tới hiệu quả giao tiếp của điều dưỡng viên. Để nâng cao mức độ tự tin này, việc xác định được các yếu tố liên quan tới nó là rất quan trong. Do đó, nghiên cứu này được tiến hành nhằm tìm hiểu các yếu tố liên quan đến mức độ tự tin của điêu dưỡng viên trong môt số tình huống giao tiếp thường gặp. Đối tượng và phương pháp nghiên cứu: Với thiết kế mổ tả cắt ngang, nghiên cứu được tiến hành trên 125 điều dưỡng tai một số bệnh viện của tỉnh Thái Nguyên và Cao Bằng. Thời gian thực hiện từ tháng 3 đển tháng 4 năm 2021. Đối tượng nghiên cứu được phát vấn thồng qua bộ câu hỏi tự điên về mức độ tự tin khi giao tiếp trong mười một tình huống thường gặp, thang điểm đánh giá gồm 4 mức độ tữ rất không tự tin (0 điểm), bình thường (1 điểm), tự tin (2 điểm), đến rất tự tin (3 điểm). Điểm tự tin trong giao tiếp là điểm tổng của tất cả các câu hỏi, tối đa là 33 điểm. Điểm càng cao thể hiện mức độ tự tin càng lớn. Kết quả: Điểm trung bình mức độ tự tin trong giao tiếp của điều dưỡng viên là $21,49 \pm$

${ }^{1}$ Viện Khoa học Sức khoẻ, Trường Đại học VinUni Chịu trách nhiệm chính: Nguyễn Hoàng Long Email: long.nh@vinuni.edu.vn

Ngày nhận bài: 10.8.2021

Ngày phản biên khoa hoc: 1.10.2021

Ngày duyệt bài: 12.10.2021
3,17. Tỷ lệ điều dưỡng tự tin ở mức trung bình chiếm đa số $(80 \%)$. Bên cạnh đó, $20 \%$ điều dưỡng được đánh giá là tự tin cao, và không có điều dưỡng nào được xếp loại không tự tin trong các tình huống giao tiếp thường gặp được khảo sát. Nghiên cứu cũng không tìm thấy sự khác biệt có ý nghĩa thống kê nào giữa điểm trung bình về mức độ tự tin trong giao tiếp giữa nhóm điều dưỡng từ 35 tuổi trở lên và dưới 35 tuổi, giữa nhóm điều dưỡng làm tại khoa lâm sàng với nhóm làm việc tại phòng ban, cận lâm sàng và khoa khám bênh, giữa nhóm điều dưỡng đã từng được đào tạo và chưa từng được đào tạo vể kỹ năng giao tiếp trước đây, cũng như giữa nhóm điêu dưỡng viên và điều dưỡng trưởng $(p>0,05)$. Kết luận: Mức độ tự tin của điều dưỡng viên trong một số tình huống thường gặp ở mức trung bình. Chưa tìm thấy bằng chứng vê vai trò của các yếu tố gồm tuổi, đơn vị công tác, vị trí công việc, và kinh nghiệm với các khóa đào tạo giao tiếp trước kia với mức độ tự tin trong giao tiếp của điều dưỡng viên.

Tư khóa: Tự tin, Giao tiếp, Điều dưỡng.

\section{SUMMARY}

FACTORS RELATED TO SELF-CONFIDENCE

IN COMMUNICATION AMONG NURSES AT HOSPITALS IN THAI NGUYEN AND CAO BANG PROVINCES, 2021

Background: The level of confidence determines the effectiveness of nurses' communication. To 
increase self-confidence of nurses, it is important to identify factors associated with it. Therefore, this study was conducted to describe some factors related to nurses' confidence in some common communication situations. Methods: A cross-sectional was conducted with 125 nurses from hospitals in Thai Nguyen and Cao Bang province. The data were collected from March to April 2021. The self-administered questionnaire with 11 common communication situations were distributed to all the selected nurses to complete. In this study we apply the Likert scale which consisted of 4 levels, from very unconfident ( 0 points), normal (1 point), confident ( 2 points), to very confident (3 points). Total score is the sum of all questions's score, with the maximum of 33 points. The higher the score, the greater the level of confidence. Results: the sample was composed by 125 nurses, of whom $80 \%$ had a moderate self-confidence in communication, with the average score was $21.49 \pm$ 3.17. In addition, $20 \%$ of nurses were rated as highly confident, and there is no nurse rated as unconfident in common communication situations surveyed. The results showed that no statistically significant differences were found between the average score of different nursing groups, such as: nurse and head nurse, upper and lower 35 years old, working in clinical and paraclinical area, and nurse has been trained and has not been trained on communication before $(p>0,05)$. Conclusion: The level of nurse's confidence in some common situations is average. No evidence was founded for the role of factors including age, work unit, job position, and experience with previous communication training courses on selfconfidence of nurses in communication.

Keywords: Self-confidence, Communication, Nurse.

\section{I. ĐĂT VẤN ĐỀ}

Hoạt động giao tiếp của điều dưỡng viên bị ảnh hưởng bởi nhiều yếu tố như đặc điểm tính cách, tình cảm, nhận thức, điều kiện môi trường xã hội và nền tảng văn hóa của mỗi người [2]. Trong số đó, mức độ tự tin trong giao tiếp là một trong các yếu tố quyết định. Mức độ tự tin ở đầy được hiểu là sự tin tưởing của điều dưỡng trong việc họ có thể, sẵn sàng và xử lý linh hoạt các tình huống giao tiếp thường gặp trong quá trình thực hiện chăm sóc nghề nghiệp của mình [4].

Trên thế giới đã có một số nghiên cứu đề cập đến vai trò của mức độ tự tin trong giao tiếp của điều dưỡng tại các cơ sở khám chữa bệnh. Tổng quan tài liệu của Mark $D$. Hecimovich và Simone E. Volet cho thấy mức độ tự tin trong giao tiếp của điều dưỡng đóng vai trò quan trọng đối với sức khỏe của bệnh nhân [8], ảnh hưởng đáng kể đến kết quả chằm sóc . Nghiên cứu của Parle $M$ (1997) cũng chỉ ra rằng khả năng giao tiếp với người bệnh của bác sĩ và điều dưỡng giúp phát hiện sớm các vấn đề về cảm xúc và ngăn ngừa các biến chứng tâm lý có thể xảy ra, góp phần nâng cao hiệu quả điều trị.
Tuy nhiên, thực tế cho thấy mức độ tự tin của điều dưỡng còn chưa cao. Ở Việt Nam, nghiên cứu của Nguyễn Ngọc Huyền năm 2019 cho thấy, điểm trung bình mức đô tự tin của điều dưỡng thực tập tại bệnh viện TW Thái Nguyên ở mức trung bình $(7,29 \pm 1,24)$. Tỷ lệ phần trăm điều dưỡng tự tin còn thấp, cụ thể trong việc thiết lập mối quan hệ chắt chẽ với người bệnh để họ có thể tìm kiếm sự trợ giúp mà không ngại ngùng là 23,3\%; giải thích về phương pháp điều trị và chăm sóc người bệnh là $21,7 \%$; mức độ tư tin về viêc hỏi người bênh bất kỳ thủ tục nào mà người bệnh không hiểu để hướng dẫn hoặc giúp đõ là $25,8 \%$; và mức độ tự tin trong việc thiết lập mối quan hê tốt trong công việc với điều dưỡng trưởng và các điều dưỡng khác trong khoa là $32,5 \%$ [1].

Một số nghiên cứu đã được tiễn hành để tìm hiểu các yếu tố liên quan tới mức độ tự tin trong giao tiếp của điều dưỡng. Ví dụ, nghiên cứu của Nguyễn Thúy Ly và cộng sự năm 2014 chỉ ra rằng nhóm điều dưỡng có kiến thức, có nhiều kinh nghiệm trong công tác điều dưỡng được đánh giá là tự tin hơn trong việc giao tiếp, trao đổi và chăm sóc toàn diện cho người bệnh [3]. Nghiên cứu của Mojtaba Fattahi Ardakani (2019) và Margaret Rosenzweig (2008) chỉ ra rằng, quá trình đào tạo kỹ năng giao tiếp, sự tự tin của bản thân giúp làm tăng mức độ tự tin của điều dưỡng [9], [7].

Như vấy, mức độ tự tin trong giao tiếp của điều dương là rất quan trọng và cần thiết phải được cải thiện. Tuy vậy, chưa có nhiều nghiên cứu được tiển hành để tìm hiểu các yếu tố liên quan tới mức độ tự tin trong giao tiếp của điều dưỡng. Đăcc biệt, do hoat động giao tiếp bi ảnh hưởng rất lớn bởi các yếu tố về văn hóa nên việc đánh giá mức độ tự tin trong giao tiếp cũng cần được xem xét ở các khu vực văn hóa cu thể. Vì vây, chúng tôi tiến hành nghiên cứu này nhằm "mô tả một số yếu tố liên quan đến mức độ tự tin trong giao tiếp của điều dưỡng viên tại một số bệnh viện của tỉnh Thái Nguyên và Cao Bằng." Hai khu vực được chọn nhằm giúp gợi mơ thông tin cơ bản về nội dung nghiên cứu ở khu vực Miền núi phía Bắc, nơi có các nét văn hóa, xã hội riêng biệt. Kết quả của nghiên cứu sẽ giúp các nhà quản lý bênh viên có những giải pháp nhằm cải thiện chất lượng giao tiếp của điều dưỡng ở khu vực này.

\section{II. ĐỐI TƯỢNG VÀ PHƯƠNG PHÁP NGHIÊN CỨU \\ 2.1 Thiết kế nghiên cứu: Mô tả cắt ngang 2.2 Địa điểm, thời gian: Nghiên cứu chọn}


chủ đích 06 bệnh viện thuộc các tuyến khác nhau tại tỉnh Thái Nguyên (Bệnh viện $A$, Bệnh viện Quốc tế Thái Nguyên, BV Lao, Bệnh viện PHCN, Bệnh viện Đại học $Y$ Thái Nguyên, BV 91) và 01 Bệnh viện Đa khoa tỉnh Cao Bằng. Đây là các bệnh viện tham gia chương trình đào tạo kỹ năng giao tiếp trong khuôn khổ chương trình chỉ đạo tuyến của bệnh viện Trung ương Thái Nguyên. Số liệu được thu thập từ tháng 3 đến tháng 4 năm 2021.

2.3 Đối tượng nghiên cứu: Điều dưỡng làm việc tại các khoa phòng khác nhau của bệnh viện tham gia nghiên cứu.

2.4 Cỡ mẫu và phương pháp chọn mẫu: Chọn thuân tiện, tất cả 125 điều dưỡng viên tham gia khóa đào tạo kỹ năng giao tiếp được mời tham gia nghiên cứu và đều chấp thuận.

2.5 Phương pháp thu thập thông tin: Nhóm nghiên cứu thực hiện phát vấn đối tượng, sử dụng bộ công cụ đánh giá mức độ tự tin trong giao tiếp của điều dưỡng trước khi đối tượng nghiên cứu bắt đầu buổi đầu tiên của đợt đào tao.

2.6 Bộ công cụ và thang đo: Bộ công cụ được xây dựng dựa trên các y văn về giao tiếp giữa điều dưỡng với người bệnh [5], có tham khảo ý kiến chuyên gia và chỉnh sửa phù hợp với thực tế. Mức độ tự tin trong giao tiếp của điều dưỡng được đánh giá theo thang điểm liker 4 mức độ, từ rất không tự tin ( 0 điểm), bình thường (1 điểm), tự tin (2 điểm), và rất tự tin (3 điểm), thông qua 11 tình huống thường gặp, ví dụ như giới thiệu bản thân, giải thích về kỹ thuật sẽ thực hiện, thể hiện sự đồng cảm, thể hiện sự không đồng tình với người khác. Điểm tự tin là điểm tổng của 11 câu hỏi, thay đổi từ 0 đến 33 điểm. Điều dưỡng được đánh giá ở ba mức là "tự tin cao", "tự tin trung bình" và "không tự tin" khi tổng điểm lần lượt là 22-33, 11-22 và 0-11.

2.7 Phân tích số liệu: Số liêu được tính toán tỷ lệ \%, giá trị trung bình và độ lệch chuẩn để mô tả đặc điểm và mức độ tự tin của đối tượng nghiên cứu. Sử dụng kiểm định student (ttest) để so sánh sự khác biệt giữa các giá trị trung bình.

2.8 Đạo đức nghiên cứu: Nghiên cứu đã được thông qua hội đồng đạo đức nghiên cứu y sinh học của Bệnh viện Trung ương Thái Nguyên.

\section{KẾT QUẢ NGHIÊN CứU}

Bảng 1. Đặc điểm chung của điều dướng tại các bệnh viện tỉnh Thái Nguyên và Cao Bằng năm 2021 ( $n=125)$

\begin{tabular}{|l|l|l|} 
Đặc điếm & $\mathbf{n}$ & $\%$ \\
\hline
\end{tabular}

\begin{tabular}{|c|c|c|c|}
\hline \multirow{2}{*}{ Giới } & Nam & 8 & 6,4 \\
\cline { 2 - 4 } & Nữ & 117 & 93,6 \\
\hline \multirow{2}{*}{ Tuổi } & $<35$ tuối & 51 & 40,8 \\
\cline { 2 - 4 } & $\geq 35$ tuối & 74 & 59,2 \\
\hline \multirow{2}{*}{$\begin{array}{c}\text { Đơn vì } \\
\text { công tác }\end{array}$} & Khoa lâm sàng & 72 & 57,6 \\
\cline { 2 - 4 } & $\begin{array}{c}\text { Phòng ban, CLS, } \\
\text { KKB }\end{array}$ & 53 & 42,4 \\
\hline \multirow{2}{*}{$\begin{array}{c}\text { Trình đồ } \\
\text { chuyên } \\
\text { môn }\end{array}$} & Sau đại họC & 3 & 2,4 \\
\cline { 2 - 4 } & Đại học/cao đăng & 113 & 90,4 \\
\cline { 2 - 4 } & Trung họC & 9 & 7,2 \\
\hline \multirow{2}{*}{ môn }
\end{tabular}

Kết quả nghiên cứu cho thấy tỷ lệ điều dưỡng là nữ chiếm đa số $(93,6 \%)$, với độ tuổi trung bình là $35,7( \pm 6,02)$ tuổi, trong đó số tuổi thấp nhất là 21 , và cao nhất là 53 tuổi. Thời gian công tác trung bình là $12,2( \pm 5,8)$ năm. Số điều dưỡng công tác tại khối lâm sàng cao hơn khối cận lâm sàng/ phòng ban, với tỷ lệ \% lần lượt là $57,6 \%$ và $42,4 \%$. Đa số đối tượng nghiên cứu có trình độ Đại học, Cao đẳng (90,4\%).

Bảng 2. Mức độ tứ tîn trong giao tiêp của điều dướng tại các bệnh viện tỉnh Thái Nguyên và Cao Bằng năm 2021

\begin{tabular}{|c|c|c|c|}
\hline Mức độ tự tin & $\mathbf{n}$ & $\mathbf{\%}$ & $\mathbf{x} \pm \mathbf{~ S D}$ \\
\hline Tự tin cao & 25 & 20,0 & $26,20 \pm 1,83$ \\
\hline Tự tị trung bình & 100 & 80,0 & $20,31 \pm 3,06$ \\
\hline Không tự tin & 0 & 0 & 0 \\
\hline Tống & $\mathbf{1 2 5}$ & $\mathbf{1 0 0 \%}$ & $\mathbf{2 1 , 4 9} \pm \mathbf{3 , 1 7}$ \\
\hline
\end{tabular}

Kết quả từ bảng trên cho thấy điểm trung bình mức độ tự tin của điều dưỡng khi giao tiếp là $21,49 \pm 3,17$. Tỷ lệ điều dưỡng có mức độ tự tin trung bình khi giao tiếp chiếm đa số $(80 \%)$. Chỉ có $20 \%$ điều dưỡng được đánh giá là có tự tin, và không có điều dưỡng nào cảm thấy không tự tin trong các tình huống giao tiếp thường gặp.

Bảng 3. Môt số yếu tố liên quan đêén mức độ tư tîn trong giao tiếp của điều dướng tại các bệnh viện tỉnh Thái Nguyên và Cao Bằng năm 2021 ( $n=125)$

\begin{tabular}{|c|c|c|c|}
\hline & $\%$ & $\begin{array}{c}\bar{x} \\
(\text { Min-Max) }\end{array}$ & $\begin{array}{c}P \\
\text { (t-test) }\end{array}$ \\
\hline \multicolumn{4}{|c|}{ Nhóm tuối } \\
\hline$<35$ tuối & 40,8 & $21,1(15-31)$ & \multirow{2}{*}{0,307} \\
\hline$\geq 35$ tuối & 59,2 & $21,7(14-33)$ & \\
\hline \multicolumn{4}{|c|}{ Khoa phòng công tác } \\
\hline Cận lâm sàng & 42,4 & $21,5(14-33)$ & \multirow{2}{*}{0,904} \\
\hline Khoa lâm sàng & 57,6 & $21,5(15-33)$ & \\
\hline \multicolumn{4}{|c|}{ Chức vụ hiện tại } \\
\hline Điều dưỡng viên & 79,2 & $21,2(14-31)$ & \multirow[b]{2}{*}{0,058} \\
\hline $\begin{array}{c}\text { ĐD trưởng } \\
\text { nhóm/khoa/BV }\end{array}$ & 20,8 & $\begin{array}{c}22,5 \\
(18-33)\end{array}$ & \\
\hline \multicolumn{4}{|c|}{ Được đào tạo KNGT } \\
\hline Đã từng & 50,4 & $22(14-33)$ & \multirow{2}{*}{0,099} \\
\hline Chưa từng & 49,6 & $21(15-31)$ & \\
\hline
\end{tabular}


\begin{tabular}{|l|l|l|l|}
\hline Dưới 50 & 59,2 & $21,5(15-33)$ & \multirow{2}{*}{0,995}
\end{tabular}

Kết quả nghiên cứu cho thấy có sự khác nhau giữa tỷ lệ \% và điểm trung bình mức độ tự tin khi giao tiếp giữa nhóm điều dưỡng trên và dưới 35 tuổi, giữa nhóm điều dưỡng làm tại khoa lâm sàng và khoa cận lâm sàng, giữa nhóm điều dưỡng viên và điều dưỡng trưởng cũng như giữa nhóm điều dưỡng đã từng được đào tạo và chưa từng được đào tạo về kỹ năng giao tiếp trước đây. Tuy nhiên, sự khác biệt này không có ý nghĩa thống kê với p>0,05.

\section{BÀN LUẬN}

Kết quả của nghiên cứu cho thấy tỷ lệ điều dưỡng tự đánh giá sự tự tin của mình ở mức trung bình là $80 \%$, và không có điều dưỡng nào cảm thấy không tự tin khi giao tiếp. Điểm trung bình mức độ tự tin trong giao tiếp của điều dưỡng là 21,49 $\pm 3,17$ điểm. Với tổng điểm tối đa 33 của thang đo, ngưỡng điểm này được đánh giá ở mức trung bình. Kết quả này cũng tương đồng với nghiên cứu của Nguyễn Ngọc Huyền năm 2019 trên các sinh viên thực tập tại bệnh viện Thái Nguyên, cho thấy mức độ tự tin trong giao tiếp của điều dưỡng cũng ở mức trung bình. Một số tình huống giao tiếp thường gặp mà điều dương chưa thực sự tự tin bao gồm: Thiết lập mối quan hê chặt chẽ với người bệnh để họ có thể tìm kiếm sự trợ giúp mà không ngại ngùng; Thiết lập mối quan hệ tốt trong công việc với điều dưỡng trưởng và các điều dưỡng khác trong khoa. Kết quả nghiên cứu cho thấy, điều dưỡng viên cần được giúp đõ để nâng cao sự tự tin trong giao tiếp.

Nghiên cứu này không tìm thấy sự khác biệt có ý nghĩa thống kê về mức đô tự tin trong giao tiếp giữa nhóm điều dưỡng từ 35 tuổi trở lên và dưới 35 tuổi. Theo quan niệm thông thường, người càng nhiều tuổi càng có nhiều kinh nghiệm và tự tin hơn khi giao tiếp. Tuy nhiên, các yêu cầu về kỹ năng giao tiếp trong chuẩn năng lực của điều dưỡng càng ngày càng cao, điều này có thể làm cho các điều dưỡng lớn tuổi chưa đáp ứng được bằng những người trẻ, vì vậy họ có thể sẽ không được tự tin khi giao tiếp so với các điều dưỡng trẻ tuổi hơn. Kết quả này cũng gợi ý rằng không chỉ điều dưỡng trẻ, mới vào nghề mà cả các đối tượng đã có kinh nghiệm cũng cần được quan tâm, rèn luyện nâng cao mức độ tự tin trong giao tiếp.

Ngoài ra, kết quả nghiên cứu cũng không thấy có sự khác biệt một cách có ý nghĩa giữa nhóm điều dưỡng viên với nhóm là điều dưỡng trưởng khoa. Điều này rất đáng quan tâm. Lý do là vì phạm vi và nội dung giao tiếp của đối tượng điều dưỡng làm quản lý rộng hơn rất nhiều so với đối tượng khác. Do đó, họ cần có kỹ năng và mức độ tự tin trong giao tiếp cao hơn. Việc nâng cao kỹ năng giao tiếp cho điều dưỡng trưởng đã được khuyến nghị rất nhiều [5],[6]. Kết quả nghiên cứu này một lần nữa nhấn mạnh yêu câu thiết yếu của việc hỗ trợ, đào tạo về giao tiếp cho các điều dưỡng làm công tác quản lý.

Trong nghiên cứu này, kết quả cũng cho thây không có sự khác biệt có ý nghĩa thống kê giữa nhóm điều dưỡng đã từng được đào tạo và chưa từng được đào tạo về kỹ năng giao tiếp trước đây. Kết quả này rất đáng quan tâm vì nó khác biêt so với các kết quả đã được công bố, thậm chí có vẻ trái ngược với lý thuyểt về tác dụng của hoạt động đào tạo. Theo Mojtaba Fattahi Ardakani và cộng sự, quá trình đào tạo kỹ năng giao tiếp giúp làm tăng mức độ tự tin của điều dưỡng một cách có ý nghĩa thống kê $(95 \% \mathrm{CI}$ : $0,311-0,699, p<0,001)[9]$. Nghiên cứu của Margaret Rosenzweig cũng chỉ ra rằng sự tự tin của sinh viên điều dưỡng khi bắt đầu các cuộc trò chuyện khó khăn đã tăng lên đáng kể cả ngay lập tức $(p<0,001)$ và 4 tháng sau $(p=$ $0,001)$ khi tham gia chương trình đào tạo mô phỏng về giao tiếp [7]. Có thể có nhiều cách lý giải cho sự khác biệt này. Thứ nhất, cõ̃ của mẫu nghiên cứu này có thể chưa đủ lớn để giúp ghi nhận sự khác biệt. Thứ hai, quan trọng hơn, các chương trình đào tao kỹ năng giao tiếp có thể chưa thực sự hiệu quả, chưa tạo ra sự khác biệt giữa người đã tham gia đào tạo và người chưa được tham gia đào tạo. Thứ ba, các lý thuyết về khoa hoc hành vi cho thấy đào tạo chỉ là một trong các phương cách để xây dựng sự tự tin. Vì vậy, tác dụng thực sự của hoạt động đào tạo trong việc giúp điểu dưỡng tự tin hớn trong giao tiếp cần tiếp tục được tìm hiểu bởi các nghiên cứu khác trong tương lai.

\section{KẾT LUẦN}

Nghiên cứu trên 125 điều dưỡng tại một số bệnh viện tỉnh Thái Nguyên và Cao Bằng năm 2021 cho thấy $80 \%$ điêu dưỡng tự tin khi giao tiếp ở mức trung bình, với điểm trung bình mức độ tự tin là $21,49 \pm 3,17$. Không tìm thây sự khác biệt có ý nghĩa thống kê về mức độ tự tin trong giao tiếp của điều dưỡng theo nhóm tuổi trên và dưới 35 tuổi, theo chức vụ điều dưỡng trưởng và điều dưỡng viên, giữa nhóm điều dưỡng làm việc tại khoa lâm sàng với phòng ban, cận lâm sàng, và giữa nhóm điều dưỡng đã được 
đào tạo về kỹ năng giao tiếp với nhóm chưa được đào tạo.

\section{TÀI LIÊU THAM KHẢO}

1. Nguyễn Ngọc Huyên (2019). Sự tự tin trong thực hành kỹ năng lâm sàng của sinh viên điêu dưỡng chính quy tại Bệnh viện trung ương Thái Nguyên năm 2019. Ṫạp chí Khơa học và công nghế Đại học Thái Nguyên, 225(01), 47-52.

2. Lương Ngọc Khuê (2012). Tăng cường năng lực quản lý điêu dưỡng. Bộ Y Tế.

3. Nguyến Thúy Ly, Yvonne Osborne và Patsty Yates (2014). Kiến thức, thái độ và sự tự tin trong thực hanh chăm sóc giảm nhẹ của điêu dưỡng tại một số bệnh viện chuyên khoa Ung bướu Hà Nôii. International journal of palliative nursing, 20(9), 448.

4. Bandura A (1977). Self-confidence: toward a unifying theory of behavioral change. Psychological Review, 84(2), 191

5. Chia-Hui W, Kathryn A, Nai-Wen K (2016). The Role of Head Nurse on Communication: A
Social Network Approach. International Journal of Future Computer and Communication, Vol. 5, No. 1, February 2016.

6. Ika C, Novieastari E, Nuraini T (2019). The role of a head nurses in preventing interdisciplinary conflicts. Enferm Clin; 29(S2): 123-127.

7. Margaret Rosenzweig et all (2008). Patient communication simulation laboratory for students in an acute care nurse practitioner program. American Journal Of Critical Care, 17(4), 364-372.

8. Mark D. Hecimovich, MSc, DC, ATC and Simone E. Volet, PhD (2009), Importance of Building Confidence in Patient Communication and Clinical Skills Among Chiropractic Students. The Journal of Chiropractic Education; 23(2): 151-164.

9. Mojtaba Fattahi Ardakani, Mohammad Ali Morowati Sharifabad, Mohammad Amin Bahrami, Amin Salehi Abargouei4 (2019). The effect of communication skills training on the self-confidence of nurses: a systematic review and meta-analysis study. Bali Medical Journal, 8(1), 144-152. P-ISSN.2089-1180, E-ISSN.2302-2914 144

\section{KHẢO SÁT VIÊC SỬ DỰG THUỐC GIẢM ĐAU VÀ NHỮNG RÀO CẢN TRONG QUẢN LÝ ĐAU UNG THƯ TRÊN BỆNH NHÂN ĐIỀU TR! TẠI BỆNH VIỆN K2}

\section{Bùi Thanh Loan', Đoàn Lực ${ }^{2}$ Phan Thị Quỳnh Nga ${ }^{3}$, Quách Phụng Linh ${ }^{3}$, Nguyễn Tứ Sơn ${ }^{1}$ \\ nhân trong quản lý đau ung thư bao gồm: không nắm được hướng dẫn dùng thuốc, quan niệm rằng thuốc giảm đau chỉ nên uống khi đau, cố gắng chịu đau, sợ tác dụng phụ và sợ dung nạp thuốc. Cần can thiệp để cải thiện vấn đề tuân thủ dùng thuốc và hạn chế các rào cản từ bệnh nhân trong quản lý đau ung thư.}

\section{TÓM TẮT}

Mục tiêu: Khảo sát việc kê đơn sử dụng thuốc giảm đau, sự tuân thủ dùng thuốc giảm đau và những rào cản trên bệnh nhân trong quản lý đau ung thư. Phương pháp: Nghiên cứu cắt ngang, sử dung bố câu hỏi thông qua hình thức phỏng vấn trực tiểp hoặc qua điên thoai. Kết quả: Tuổi trung bình của 46 bênh nhân là 57,5 ; ung thư phế quản phổi là loại ung thư phổ biến nhất. Phần lớn bênh nhân còn đau mức độ trung bình $(63 \%)$ và nặng $(21,7 \%)$. Phác đồ giảm đau phổ biến nhất được duy trì là tramadol + paracetamol. Tỷ lệ không tuân thủ dùng thuốc giảm đau là $65,2 \% ; 19,6 \%$ bệnh nhân không mô tả đúng hướng dẫn dùng thuốc của cán bộ y tế.Từ 47,5\% đến 100\% bệnh nhân đồng ý hoàn toàn với các vấn đề: như thuốc giảm đau chỉ nên dùng khi đau, đau là diến biến tự nhiên của bệnh cân phải chịu đựng, sợ tác dụng phụ và sợ thuốc giảm đau sẽ mất dần tác dụng. Kết luận: Gần $2 / 3$ bệnh nhân không tuân thủ việc sử dụng thuốc giảm đau; những rào cản chính từ bệnh

\footnotetext{
${ }^{1}$ Trường Đại hoc Dước Hà Nôii

${ }^{2}$ Trung tâm Chăm Sóc Giảm Nhẹ, Bệnh viện K ${ }^{3}$ Bênh viênK

Chịu trách nhiệm chính: Bùi Thanh Loan

Email: buithanhloandkh@gmail.com

Ngày nhận bài: 9.8.2021

Ngày phản biên khoa hoc: 4.10 .2021

Ngày duyệt bài: 14.10.2021
}

Tư khóa: Quản lý đau ung thư, rào cản, tuân thủ điều trị, bệnh viện $\mathrm{K}$.

\section{SUMMARY \\ THE USE OF ANALGESICS AND BARRIERS TO CANCER PAIN MANAGEMENT IN K2 HOSPITAL}

Objectives: To investigate analgesic prescribing, pain medication adherence and patient barriers to cancer pain management. Methods: Across-sectional studywas conducted, patients wereface-to-face interviewedor via telephonewith a questionnaire. Results: 46 patientsparticipated the study (mean age: 57.5). Lungcancer wasthe most common cancer. Most patients weresuffering moderate pain $(63 \%)$ and severe pain $(21.7 \%)$. The most common analgesic regimen was tramadol+paracetamol. The rate of patients not adherenceis $65.2 \% ; 19.6 \%$ of patients did not know the instructions of using analgesics. From $47.5 \%$ to $100 \%$ of patients agree with issues such as pain medication should only be used when pain, pain is a natural course of the disease that must be endured, fear of side effects and fear of pain medication will gradually lose its effect. Conclusion: 